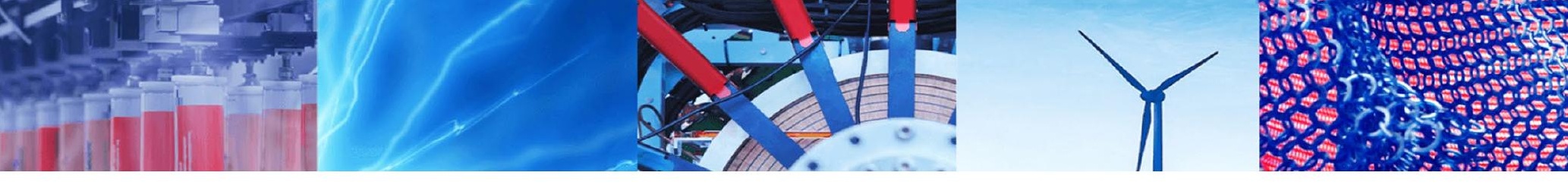

Research Article

\title{
The properties of the mesocarp fibers of patauá, a multiple-use palm from the Amazonia forest
}

\author{
Orimax Monteiro Cruz ${ }^{1} \cdot$ Rafael Lucas Figueiredo de Souza $^{3} \cdot$ Raquel Rocha de Freitas $^{1} \cdot$ Lyssa Martins de Souza $^{4}$. \\ Edina Ruth Mendes Leal Mafra ${ }^{2} \cdot$ Breno Marques da Silva e Silva $^{1} \cdot$ Lina Bufalino ${ }^{4}$ (i)
}

(c) Springer Nature Switzerland AG 2019

\begin{abstract}
Patauá is very little studied palm tree of the Amazonia that shows lignocellulosic fibers covering the seed that can be easily removed. This work aimed to determine some properties of the patauá mesocarp fibers in the raw and alkali treated conditions for biomaterial applications. The wastes from the depulping of the patauá were obtained in commercial establishments at Macapá-Amapá-Brazil. The fibers were manually removed from the seeds. One portion of $10 \mathrm{~g}$ of fibers was treated by immersion in $1000 \mathrm{~mL}$ of sodium hydroxide $(\mathrm{NaOH})$ aqueous solution at $5 \%$ kept at $100^{\circ} \mathrm{C}$ for $1 \mathrm{~h}$ and under mechanical stirring. The following characterizations were performed: fiber length; scanning electron microscopy; width measurement; and basic density. The patauá mesocarp fibers are actually fiber bundles with erosions in the cell wall blocked by protrusions. They are suitable for large-scale production in both raw and alkali treated conditions. The improvements achieved by alkali treatment includes unblocking of superficial erosions, decrease of the width, length and basic density of the fibrous units, and increase of crystalline index. Individualization of fiber cells was not completed by the alkali treatment proposed in this work.
\end{abstract}

Keywords Aspect ratio · Cellulose fiber · Silica bodies · Basic density · Alkali treatment

\section{Introduction}

Brazil's broad climatic and geomorphologic variety is responsible for the several important biomes and ecosystems, which lodge about $10 \%$ to $20 \%$ of the world's known living species. Among them, the highest biodiversity is in the Amazon rainforest, which maintains a dynamic and suitable environmental heterogeneity for palms (Arecaceae) diversification [1].

Patauá (Oenocarpus bataua Mart.) is a palm that occurs throughout all the Amazonia [8]. The term Oenocarpus that names the genus concerns its most traditional use, the fruit juice commonly named wine (oinos = wine; karpos $=$ fruit) for food [2]. The depulping process to obtain the wine is similar to the one used for the well-known açaí, after which a waste composed of the seeds covered by hard lignocellulosic fibers that can be easily removed by hand remains [5].

Plant fibers are very attractive for biomaterials production due to properties such as high content of cellulose, low density, non-abrasiveness, nontoxicity, low cost, and biodegradability. However, the lack of good interfacial adhesion between fibers and matrix, low melting point, and water sensitivity make the use of plant fiber-reinforced composites less attractive [11]. Some drawbacks hindering plant fiber application may be overcome through alkaline treatment, which increases surface roughness resulting in better mechanical interlocking and raises the amount of

$\triangle$ Lina Bufalino, linabufalino@yahoo.com.br|' Forestry Science School, University of Amapá State, Presidente Vargas st. 650, Macapá, AP 68900-070, Brazil. ²Environmental Engineering School, University of Amapá State, Presidente Vargas st. 650, Macapá, AP 68900-070, Brazil. ${ }^{3}$ Forestry Science Department, Federal University of Lavras, Campus Universitário, Lavras, MG 37200-000, Brazil. ${ }^{4}$ Agrarian Science Institute, Federal Rural University of Amazonia, Presidente Trancredo Neves av. 2501, Belém, PA 66077-830, Brazil. 
cellulose exposed on the fiber surface, thus increasing the number of possible reaction sites [14].

Up to this moment, most investigations on patauá concern ecological aspects [4] and nutritional value of the fruit [17], hence the potential of the apparently very rigid fibers covering the surface of the patauás seeds for biomaterials purposes needs to be explored for the first time. Therefore, this work aimed to determine some properties of the patauá mesocarp fibers in the raw and alkali treated conditions that are relevant for biomaterial applications.

\section{Materials and methods}

The wastes from the depulping of the patauá were obtained in one commercial establishment at MacapáAmapá-Brazil, which hosts Amazon Forest. The material was washed and the fibers were handily removed from the surface of the seeds (Fig. 1). One portion of $10 \mathrm{~g}$ of fibers was treated by immersion in $1000 \mathrm{~mL}$ of sodium hydroxide $(\mathrm{NaOH})$ aqueous solution at $5 \%$ kept at $100^{\circ} \mathrm{C}$ for $1 \mathrm{~h}$ and under mechanical stirring.

The following characterizations were performed: fiber length using a caliper with $0.001 \mathrm{~cm}$ of precision; scanning electron microscopy (SEM) using a TM3030 Plus (HITACHI) microscopy at $10 \mathrm{kV}$; width using the Software ImageJ to measure the fibers of the SEM micrographs; and basic density according to Wakiyama et al. [22].

The variables width, length, and basic density of the raw and alkali-treated fibers were compared using Students' t-tests at $5 \%$ of significance.

The diffractograms were recorded on a PANalytical diffractometer model X'Pert Pro 3 MPD (PW 3040/60) with a goniometer PW3050/60 $(\theta-\theta)$, operating at $40 \mathrm{kV}$, $40 \mathrm{~mA}$, and $\mathrm{Cu}(\mathrm{Ka} 1=1,540,598 \AA)$ radiation, and $\mathrm{K} \beta$ filter of $\mathrm{Ni}$. The samples were placed on aluminum holders and scanned in $2 \theta \mathrm{min}^{-1}$ ranges varying from $5.0^{\circ}$ to $37.5^{\circ}$. The crystalline index $(\mathrm{Cl})$ was calculated from the maximum intensity of the (002) crystalline peak and the minimum intensity between the two main crystalline peaks (Eq. 1), as recommended by Segal et al. [21].

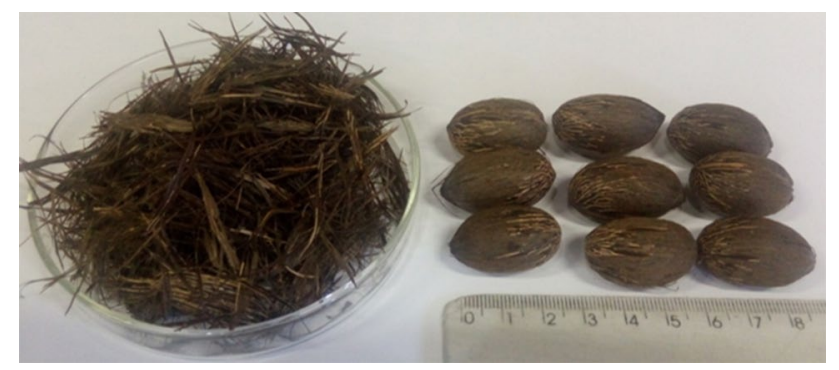

Fig. 1 Separated fibers and seeds of patauá
$\mathrm{Cl}=\left(\left(\mathrm{I} \_002-\mathrm{lam}\right) / \mathrm{I} \_002\right) * 100$

where

$\mathrm{Cl}=$ crystalline index (\%) (a.u.);

lam $=$ intensity between the two main crystalline peaks located at $2 \theta=18^{\circ}$ (a.u.);

$1002=$ maximum intensity of the (002) lattice diffraction.

\section{Results and discussion}

The SEM micrographs illustrated numerous erosions on the outer surface of the patauá fibrous units witch are completely obstructed in the raw condition, but cleared after alkali treatment. In the raw condition the structures are round-shaped, while they are flat shaped and show smaller width after alkali treatment (Fig. 2).

Other works showed that the protrusions that block the fibers of palms are composed of silica $[6,13]$. These structures have already been identified in the fibers from other parts and species of palm trees, like in the waste empty fruit bunches of oil palm Elaeis guianensis [13] and in both the seed and mesocarp fibers of Euterpe oleraceae [6]. The removal of silica and other surface impurities as observed for the treated in comparison to raw patauá fibrous structures (Fig. 2a, d) can be expected to improve the adhesion properties of the fibers to binders and ultimately improve the properties of the composite [16].

Besides the shape, the alkali treatment of patauá fibers resulted in surface modification involving removal of the surface impurities (Fig. 2b, e). Alkali treatment with sodium hydroxide $(\mathrm{NaOH})$ removes natural fats and waxes from the cellulose surfaces thus revealing chemically reactive functional groups like -OH and improving the fiber-matrix interface bonding [16].

The reduction of the width in the treated condition (Fig. 2b, e) may be attributed to lateral cleaving among fiber structures which occur bonded to each other by amorphous materials forming bundles in the raw condition (Fig. 2c). In alkaline condition, amorphous hemicelluloses are easily hydrolyzed, while lignin may be decomposed into soluble fragments of low molecular weight [3]. It should be noted that the alkali treatment turned individual fibers slacked from each other, but not completely separated (Fig. 2f). For the production of composites in the industry scale, fiber bundles are weak points in the composites which make little contribution to strength and toughness [23]; hence alkali-treated patauá fibers are more suitable for application as reinforcements.

The alkali treated patauá fibers showed significant decrease of the width, length and basic density in comparison to raw patauá fibers (Table 1 ). 

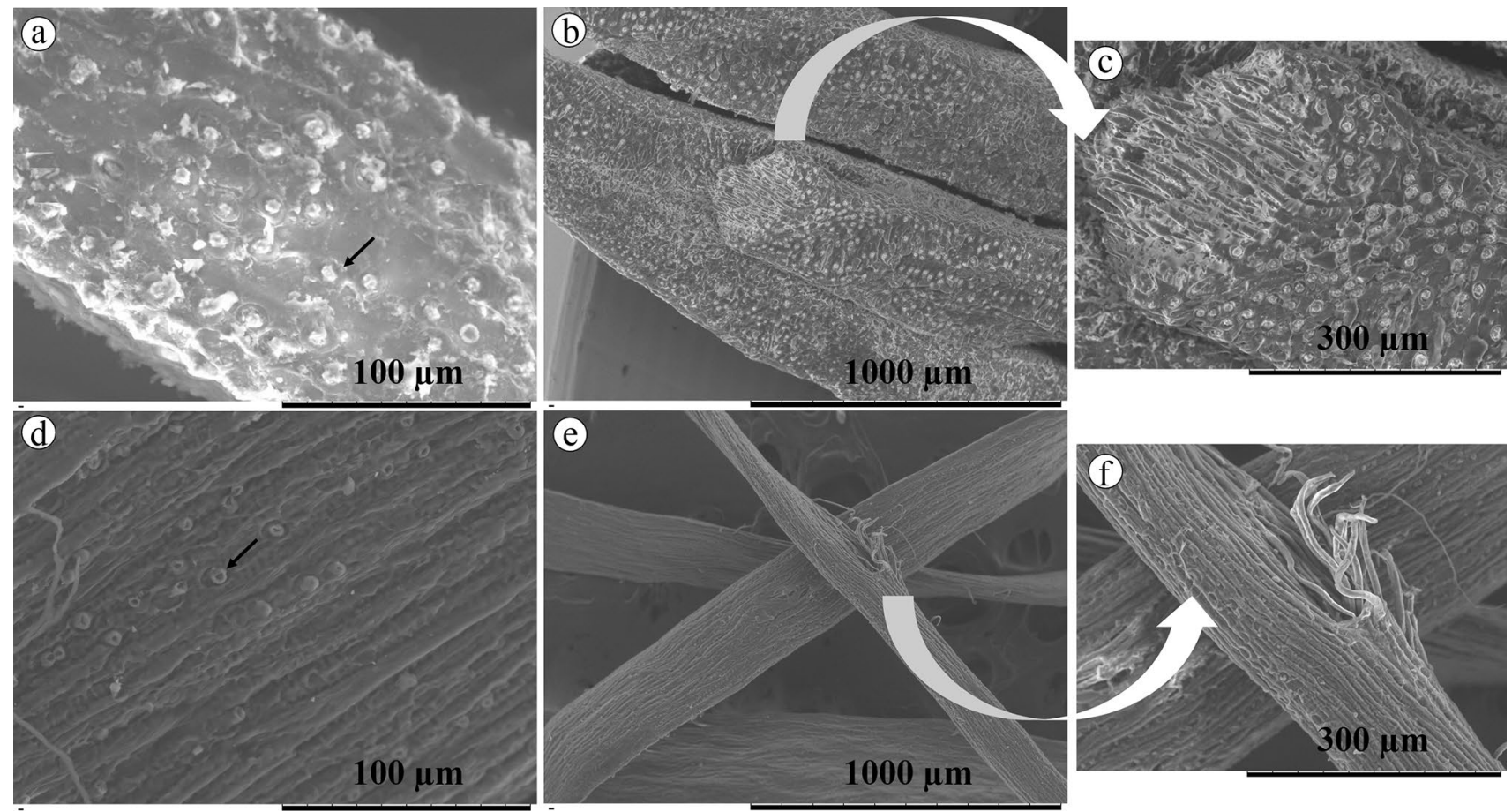

Fig. 2 Morphology of the raw (a, b, c) and alkali treated (d, e, f) patauá fibrous units analyzed by SEM micrographs. Arrows highlight blocked and unblocked erosions in the surface of raw (a) and treated (d) conditions, respectively

Table 1 Mean \pm standard deviation of the properties of the raw and alkali treated patauá mesocarp fiber bundles

\begin{tabular}{lrrr}
\hline Trait & \multicolumn{1}{l}{ Raw } & Alkali treated & Student t value \\
\hline Width $(\mathrm{mm})$ & $0.27 \pm 0.15$ & $0.19 \pm 0.75$ & $3.2366^{*}$ \\
Length $(\mathrm{mm})$ & $25.14 \pm 5.49$ & $12.72 \pm 4.91$ & $11.6009^{*}$ \\
$\begin{array}{c}\text { Basic density } \\
\left(\mathrm{g} . \mathrm{cm}^{-3}\right)\end{array}$ & $0.852 \pm 0.061$ & $0.484 \pm 0.15$ & $11.9398^{*}$ \\
\hline
\end{tabular}

"Significant according to Students' $t$ test at $5 \%$

After alkali pretreatment the length of the fibrous units decreased by about half in relation to raw fibrous units, which may be attributed to the removal of noncellulosic components (lignin and hemicelluloses) and individualization of the fibers that may be primarily attached to each other [12], but not completely aligned by their extremes across their length, as showed in Fig. 3.

Another reason for fiber shortening would be disruption of destruction of crystalline zones of the cellulose microfibrils [18], which may be analyzed through X-ray diffraction discussed later on. Fiber length decrease is disadvantageous because pull-out effect is easier when the fibers are applied as composite reinforcement [9]. It should be noted that neither width nor the length showed by patauá fibrous units correspond to individual

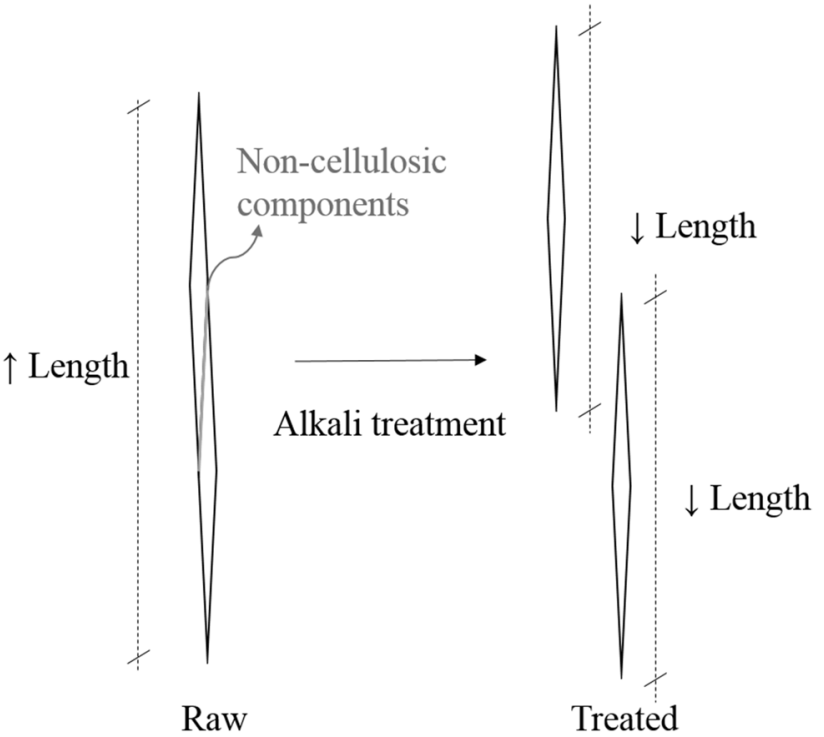

Fig. 3 Scheme of the hypothesis for patauá fiber shortening through alkali treatment

fiber cells for sure, which would demand microscopic analysis of macerates.

High aspect ratio of the fibrous units (length/diameter) applied as reinforcement may contribute to increased mechanical strength of composite materials [20]. The alkali 


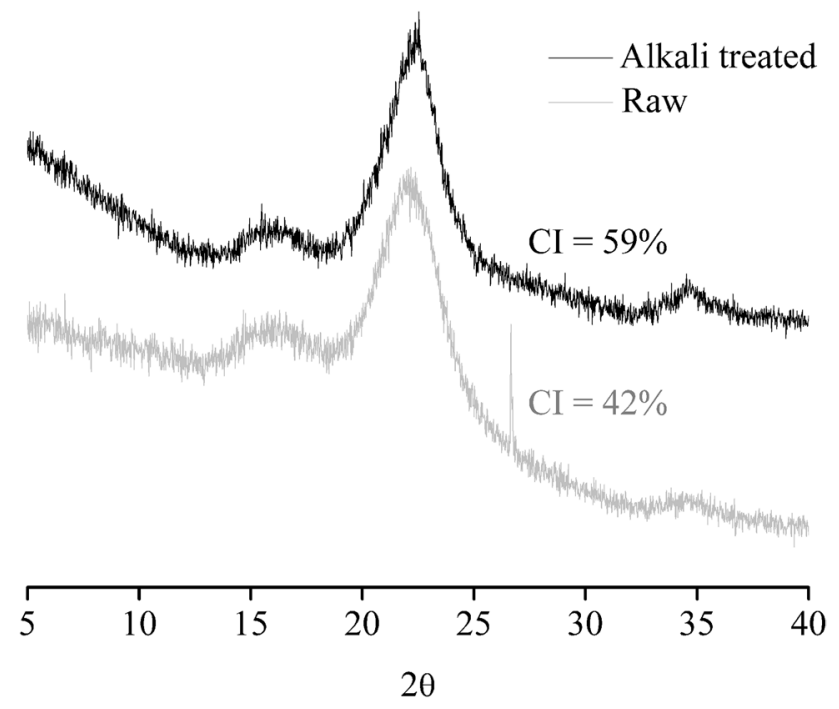

Fig. 4 Diffractograms and crystalline index $(\mathrm{Cl})$ of the raw and alkali treated patauá fibers

pretreatment decreased this parameter due to considerable decrease in fibrous unit length. Raw and alkali treated patauá fibrous units exhibited mean aspect ratio of 93 and 67 , respectively, which classifies them as suitable for largescale production because the diameter multiplied by 100 is higher than the length [10]. For composites produced with short fibers, the fibers are usually randomly dispersed within the matrix. Due to the short length of the fibers, the improved properties imparted to the composite from the fibers is limited, but this can be improved by aligning the fibers in the load direction [7].

The decrease of the basic density after alkali treatment may be attributed to the partial removal of non-cellulosic components and the increase of the porosity of the fibrous units as observed in the SEM images. The lower density in the treated patauá fibrous units may be advantageous if the matrix fills the unblocked piths increasing the strength of the composite [19]. The basic density of the raw patauá fibers is close to that found for similar açaí mesocarp fibers of $0.812 \mathrm{~g} \cdot \mathrm{cm}^{-3}$ [5].

The X-ray diffractograms show peaks related to cellulose I around $2 \theta=16^{\circ}$ e $22^{\circ}$, which corresponds to 101 and 002 planes, respectively. The later peak corresponds to the native cellulose peak. The same pattern was observed for alkali treated patauá fibers. However, the peak located at $22^{\circ}$ of the treated fibers showed shape alteration with decrease in the width, besides a remarkable raise of the crystalline index from $42 \%$ to $59 \%$ (Fig. 4). The intensity and thinning of the peaks of the alkalinized fibers characterize the removal of non-cellulosic components, which raises the proportion of cellulose and, consequently the crystalline index. This condition provides improved toughness and tension strength for the fiber [15]. In addition, the increase of the crystalline index indicates that length shortening of the fibers is probably related to the fiber isolation instead of to the degradation of the crystal zones of the cellulose microfibrils [18].

\section{Conclusions}

The patauá mesocarp fibers are actually fiber bundles with erosions in the cell wall blocked by protrusions. They are suitable for large-scale production in both raw and alkali treated conditions. The improvements achieved by alkali treatment includes unblocking of superficial erosions, decrease of the width, length and basic density of the fibrous units, and increase of crystalline index. Individualization of fiber cells was not completed by the alkali treatment proposed in this work.

Acknowledgements The authors gratefully acknowledge the National Council for Scientific and Technological Development (CNPq) and Coordination for the Improvement of Higher Education Personnel (Capes).

Funding This study was funded by National Council for Scientific and Technological Development (CNPq) (Grant No. 431553/2016-5).

\section{Compliance with ethical standards}

Conflict of interest The authors declare that they have no conflict of interest.

\section{References}

1. Alvez-Valles CM, Balslev H, Garcia-Villacorta R, Carvalho FA, Menini Neto $L$ (2018) Palm species richness, latitudinal gradients, sampling effort, and deforestation in the Amazon region. Acta Bot Bras 32:527-539. https://doi.org/10.1590/0102-33062017ab b0400

2. Balick MJ (1988) Jessenia and Oenocarpus: neotropical oil palms worthy of domestication. Food and agriculture organization of the United Nations, Rome

3. Barneto AG, Vila C, Ariza J (2011) Eucalyptus kraft pulping production: thermogravimetry monitoring. Thermochim Acta 520:110-120. https://doi.org/10.1016/j.tca.2011.03.027

4. Bastos LLS, Ferraz IDK, Lima Junior MJV, Pritchard HW (2017) Variation in limits to germination temperature and rates across the seed-seedling transition in the palm Oenocarpus bataua from the Brazilian Amazon. Seed Sci Technol 45:1-13. https:// doi.org/10.15258/sst.2017.45.1.05

5. Bufalino L, Guimarães A, Silva B, Souza R, Melo I, Oliveira D, TrugiIho $P$ (2018) Local variability of yield and physical properties of açaí waste and improvement of its energetic attributes by separation of lignocellulosic fibers and seeds. J Renew Sustain Energy 10:1-10. https://doi.org/10.1063/1.5027232

6. de Cordeiro MA, de Almeida O, Rodrigues EMS, de Chaves Neto AMJ, Machado NT (2019) Ethanol production through enzymatic hydrolysis of açaí seed (Euterpe oleracea Mart). Revista Brasileira 
de Energias Renováveis 8:122-152. https://doi.org/10.5380/rber. v8i1.53977

7. Goodship V, Middleton B, Cherrington R (2016) Design and manufacture of plastic components for multifunctionality. Elsevier, Oxford

8. Henderson A, Galeano G, Bernal R (1995) Field guide to the palms of the Americas. Princeton University Press, New Jersey

9. Joseph K, Medeiros ES, Carvalho LH, Carvalho LH (1999) Compósitos de matriz poliéster reforçados por fibras curtas de sisal. Polímeros: Ciência e Tecnologia 9:136-141. https://doi. org/10.1590/S0104-14281999000400023

10. Kalia S, Kaith BS, Kaur I (2011) Cellulose fibers: bio- and nanopolymer composites green chemistry and technology. Springer, Berlin

11. Kalia S, Thakur K, Celli A, Kiechel MA, Schauer CL (2013) Surface modification of plant fibers using environment friendly methods for their application in polymer composites, textile industry and antimicrobial activities: a review. J Environ Chem Eng 1:97-112. https://doi.org/10.1016/j.jece.2013.04.009

12. Kim JT, Netravali AN (2010) Mercerization of sisal fibers: effect of tension on mechanical properties of sisal fiber and fiberreinforced composites. Compos Part A Appl Sci Manuf 41:12451252. https://doi.org/10.1016/j.compositesa.2010.05.007

13. Law K-N, Daud WRW, Ghazali A (2007) Morphological and chemical nature of fiber strands of oil palm empty-fruit-brunch (OPEFB). BioResources 2:351-362

14. Li X, Tabil LG, Panigrahi S (2007) Chemical treatments of natural fiber for use in natural fiber-reinforced composites: a review. J Polym Environ 15:25-33. https://doi.org/10.1007/s1092 4-006-0042-3

15. Maier C, Calafut T (1998) Polypropylene: the definitive user's guide and databook. Plastic Design Library. Elsevier, New York

16. Ndazi BS, Karlsson S, Tesha JV, Nyahumwa CW (2007) Chemical and physical modifications of rice husks for use as composite panels. Composites 38:925-935. https://doi.org/10.1016/j. compositesa.2006.07.004

17. da Rodrigues AMC, Darnet S, da Silva LHM (2010) Fatty acid profiles and tocopherol contents of buriti (Mauritia flexuosa), patawa (Oenocarpus bataua), tucuma (Astrocaryum vulgare), mari (Poraqueiba paraensis) and inaja (Maximiliana maripa) fruits. J Braz Chem Soc 21:2000-2004. https://doi.org/10.1590/ S0103-50532010001000028

18. Rosa MF, Medeiros ES, Malmonge JA, Gregorski KS, Wood DF, Mattoso LHC, Glenn G, Orts WJ, Imam SH (2010) Cellulose nanowhiskers from coconut husk fibers: effect of preparation conditions on their thermal and morphological behavior. Carbohydr Polym 81:83-92. https://doi.org/10.1016/j.carbpol.2010.01.059

19. Rosa SML (2007) Estudo das propriedades de compósitos de polipropileno com casca de arroz. Dissertation, Federal University of Rio Grande do Sul

20. Santos P, Spinacé MAS, Fermoselli KKG, Paoli M (2009) Effect of the processing method and curauá fiber treatment on the properties of polyamide- 6 composites. Polímeros 19:31-39. https:// doi.org/10.1590/S0104-14282009000100010

21. Segal L, Creely JJ, Martin AE, Conrad CM Jr (1959) An empirical method for estimating the degree of crystallinity of native cellulose using the X-ray diffractometer. Text Res J 29:786-794. https://doi.org/10.1177/004051755902901003

22. Wakiyama M, Hayashi H, Kishimoto A (2010) Alumina based low permittivity substrate utilizing superplastically foaming method. J Ceram Soc Jpn 118:1090-1093. https://doi.org/10.2109/jcers j2.118.1090

23. Yang W, Araki H, Kohyama A, Thaveethavorn S, Suzuki H, Noda $T$ (2004) Process and mechanical properties of in situ silicon carbide-nanowire-reinforced chemical vapor infiltrated silicon carbide/silicon carbide composite. J Am Ceram Soc 87:172017255. https://doi.org/10.1111/j.1551-2916.2004.01720.x

Publisher's Note Springer Nature remains neutral with regard to jurisdictional claims in published maps and institutional affiliations. 